\title{
ELECTROCARDIOGRAPHIC STUDIES DURING OPERATION FOR COARCTATION OF THE AORTA
}

\author{
BY \\ MARIANO M. ALIMURUNG* AND ROBERT M. SMITH \\ From the Department of Pediatrics, Harvard Medical School, and the Children's Hospital, Boston, Mass.
}

Received July 1, 1950

Considerable attention has recently been focussed upon the disturbance of cardiac rhythm that may occur during intrathoracic surgery (Meek et al., 1937, and Burstein, 1946). These arrhythmias may vary from the relatively innocuous nodal rhythm and shifting pacemaker to cardiac standstill and ventricular fibrillation. Several initiating factors have been described, among which are cyclopropane anæsthesia, endotracheal intubation, cutting and spreading of ribs, hilar stimulation, opening of the pericardium, and dislocation of the heart (Burstein, 1947). The mechanisms by which such abnormal cardiac action has been brought into play have not always been clearly defined. In certain cases increased vagal tone or direct vagal stimulation has appeared to be the most probable cause. The work of Sloan (1949) showing the increase in vagal sensitivity with anoxia has shed considerable light on this. It seems clear then that hypoxia and hypercapnœa play a very important role in precipitating these abnormalities, whether mediated through a vagal mechanism or not.

Surgery for coarctation of the aorta has been complicated by the occurrence of several serious disturbances of cardiac function during or shortly after operation (Shapiro, 1949, and Clagett, 1949). In 100 operations reported recently by Gross (1950), there appeared to be three phases of the operation during which cardiac irregularities are especially apt to occur. The first is during the period of hypertension following the clamping of the aorta. This has proved even more hazardous if the subclavian artery also has been occluded. One patient died three days after operation and necropsy showed cerebral hæmorrhage; both aorta and subclavian artery had been clamped off during aortic anastomosis, and it is believed that the resultant excessive hypertension caused the cerebral hæmorrhage. Another patient had severe convulsions during this phase.

The second danger point proved to be immediately after the release of the aortic clamps. One patient died suddenly at this juncture, and temporary cardiac arrest occurred in three, and shock in several more. Other surgeons are known to have encountered difficulties of similar nature at this point.

The end of the operation marks the third phase that has been associated with a number of cardiac disturbances. Two patients developed severe shock at the end of operation and subsequently died.

Only one patient, who developed marked pulmonary œedema and died shortly after the opening of the chest, showed a severe disturbance of cardiac function at an interval unrelated to the three just mentioned.

Many of these accidents were quite unrelated to vagal reflexes. Shock and death on release of the aortic clamps were probably due to rapid change in hemodynamics effected by sudden removal of peripheral resistance added to previous blood loss. Shock following cyclopropane

* Fellow in Medicine, Children's Hospital and House of the Good Samaritan, Boston; Research Fellow, Harvard Medical School; and Assistant Professor of Medicine (on leave of absence), Santo Tomas University, Manila. 
anæsthesia was apparently due to the factors brought into play under long use of that agent, namely, sustained blood pressure in spite of marked blood loss, followed by sudden fall of blood pressure when the anæsthetic is removed (Dripps, 1947).

Both these shock-like reactions have subsequently been avoided by slow removal of aortic clamps, more adequate replacement of blood loss, and the use of ether instead of cyclopropane anæsthesia.

The cerebral hæmorrhage and convulsions noted were not accompanied by recognizable arrhythmias but, in themselves, may be interpreted as being manifestations of an overloaded cardiovascular system. Prevention of such reactions has been attempted by keeping the blood pressure below excessive levels: this has been accomplished by delayed replacement of blood until the maximum rise in blood pressure has passed.

Although the above explanations have served as practical guides, more accurate analysis of cardiac activity was indicated for better understanding of abnormal heart action during operation. It seemed especially important to find out whether the clamping of the aorta, or the subsequent release of the clamps, had any specific effect on the cardiac rhythm. The present study was consequently undertaken of the electrocardiogram during operation for coarctation of the aorta.

\section{Clinical Material and Method}

Ten cases of coarctation of the aorta form the basis of this study. In all instances, the preoperative diagnosis was well established by the usual diagnostic criteria (Reifenstein et al., 1947). Seven were males and three females. They ranged from 11 years to 35 years of age, with an average of 18 years.

All were operated upon by Dr. Robert E. Gross during the period from January to September, 1949. In 7, excision of the stenosed portion of the aorta followed by end-to-end anastomosis (Gross, 1945) was done; the other 3 necessitated vascular grafting (Gross, 1945) in view of the unusual length of the coarctation. All of them tolerated the operation satisfactorily. However, Case 3 developed renal failure post-operatively with oliguria, further rise of blood pressure, mental disorientation, and terminal pulmonary œdema: this complication was presumably caused by excessive sodium being given inadvertently, and necropsy showed the aortic graft to be perfectly intact. This case was the only one in the series with another associated cardiac defect, namely, rheumatic mitral insufficiency and stenosis. The other 9 in this series are doing well since the operation.

Pre-operative medication consisted of $0.6 \mathrm{mg}$. of atropine and either $0.16 \mathrm{mg}$. of morphine or $200 \mathrm{mg}$. of nembutal. Induction of anæsthesia was begun with either pentothal or nitrous oxide. This was then followed and maintained throughout the operation with endotracheal ether, with circle absorption technique.

Electrocardiograms were taken both before and during the operation, in the first two cases practically continuously during the surgical procedure. In the subsequent cases, long strip tracings were taken during important phases of the operation; namely, induction of anæsthesia, mediastinal exploration and dissection of the aorta, clamping of the aorta, release of the aortic clamps after primary anastomosis or vascular grafting, and closure of the chest.

The electrocardiograms were all recorded by means of the direct-writing Sanborn Viso-Cardiette. The pre-operative electrocardiograms included the three standard bipolar limb leads, the three augmented unipolar limb leads, and six unipolar chest leads (V1-V6). During the operation, records with the three standard limb leads were taken whenever possible or at least long strips of one bipolar limb lead.

\section{RESULTS}

The-electrocardiographic features observed in these 10 cases, both before and during the operation, are summarized in Table I. More detailed analyses are presented in Table II. While Cases 2 and 7 had pre-operative electrocardiograms within normal limits, the remaining 8 shown were abnormal. Seven showed left ventricular hypertrophy as is often observed in this condition. 
TABLE I

\section{EleCtrocardographic Features}

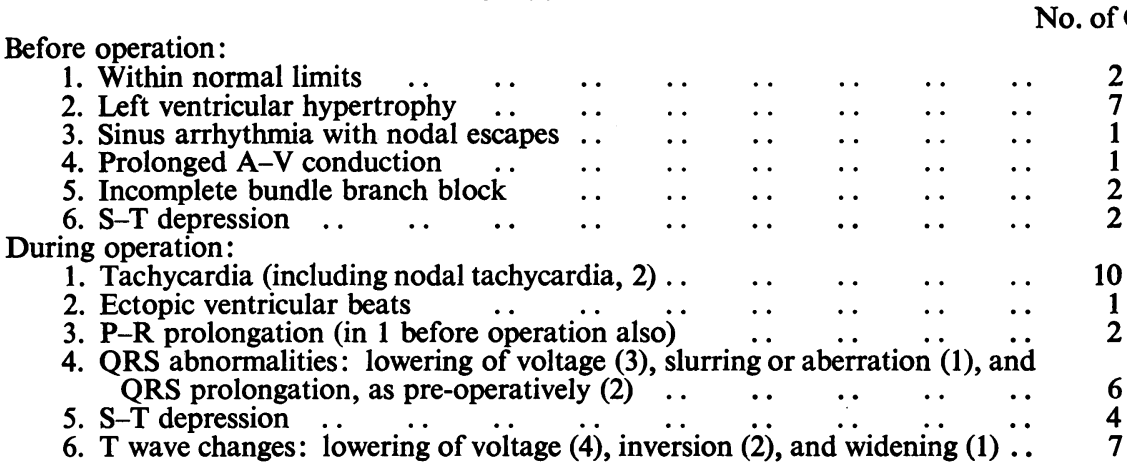

Normal sinus rhythm was present in all, except for Case 5, which showed a rather slow sinus arrhythmia with occasional nodal escapes. Cases 9 and 10 had a QRS duration longer than $0 \cdot 10$ but not beyond $0 \cdot 12$ sec., which was interpreted as incomplete bundle branch block (Burch $e t$ al., 1949). In addition, Case 9 also had a $P-R$ interval of $0 \cdot 21$ sec., against the expected normal of $0.19 \mathrm{sec}$. for her age and heart rate. The S-T segment depressions noted in Cases 4 and 10 were not more than $0.5 \mathrm{~mm}$. below the base-line.

In Table II, it is evident that some change in the electrocardiogram developed in all instances. The most uniform feature was the increase in heart rate which occurred during the induction of anæsthesia and persisted throughout the operation. In 8 cases this was an ordinary sinus tachycardia; in 2, however, the pacemaker shifted from the sinus node to the A-V node during the operation, with the nodal rhythm at a faster rate than the preceding sinus rhythm. No other arrhythmia was noted except for ectopic ventricular beats in Case 6.

Two instances of prolonged A-V conduction were observed. In Case 5, the P-R interval lengthened from a normal of 0.16 to 0.19 sec., at the moment of opening the chest. It remained so until the closure of the chest, when it came down to $0 \cdot 18 \mathrm{sec}$, the upper limit of normal for the heart rate and age of the patient. In Case 9, the P-R interval was 0.21 sec. at the start of the operation with a heart rate of $84 \mathrm{a}$ minute, and as it became $0.22 \mathrm{sec}$. during the clamping of the aorta when the heart rate increased to 105 there was some functional lengthening. Under normal circumstances, the $\mathrm{P}-\mathrm{R}$ interval should shorten as the heart rate increases.

On the other hand, the two cases with pre-operative prolongation of the QRS interval continued to show this abnormality throughout the operation, although their heart rates became faster.

Lowering, slurring, or aberration of the QRS complexes, as a rule, was never matked. It developed usually during the early part of the operation and was probably related to positional shift of the heart, especially when lowering of the QRS occurred only in one lead. In some instances, however, the QRS changes were accompanied by S-T and T wave abnormalities. These changes seemed to start during the opening of the chest but tended to become more evident during the clamping of the aorta and at times even earlier, that is, during mediastinal exploration and dissection of the aorta. In Case 4, the S-T depression reached as much as $2 \mathrm{~mm}$. below the base-line, and in Case 10 the T III became as deeply inverted as $5 \mathrm{~mm}$. Similarly, in Case 6, the occasional ectopic ventricular beats occurred slightly more frequently during the aortic clamping than at any other phase of the operation.

During the release of the clamps and subsequently during the closure of the chest, the electrocardiogram generally started to show evidence of improvement. This consisted either in increase of QRS voltage, diminution or disappearance of S-T depression, or improvement of the T waves. Again, in Case 6, the ectopic ventricular beats became less frequent until they disappeared completely. In Case 5, however, $T$ I continued to be less upright than before operation; actually it had been gradually dropping in voltage since the start of the operation. 


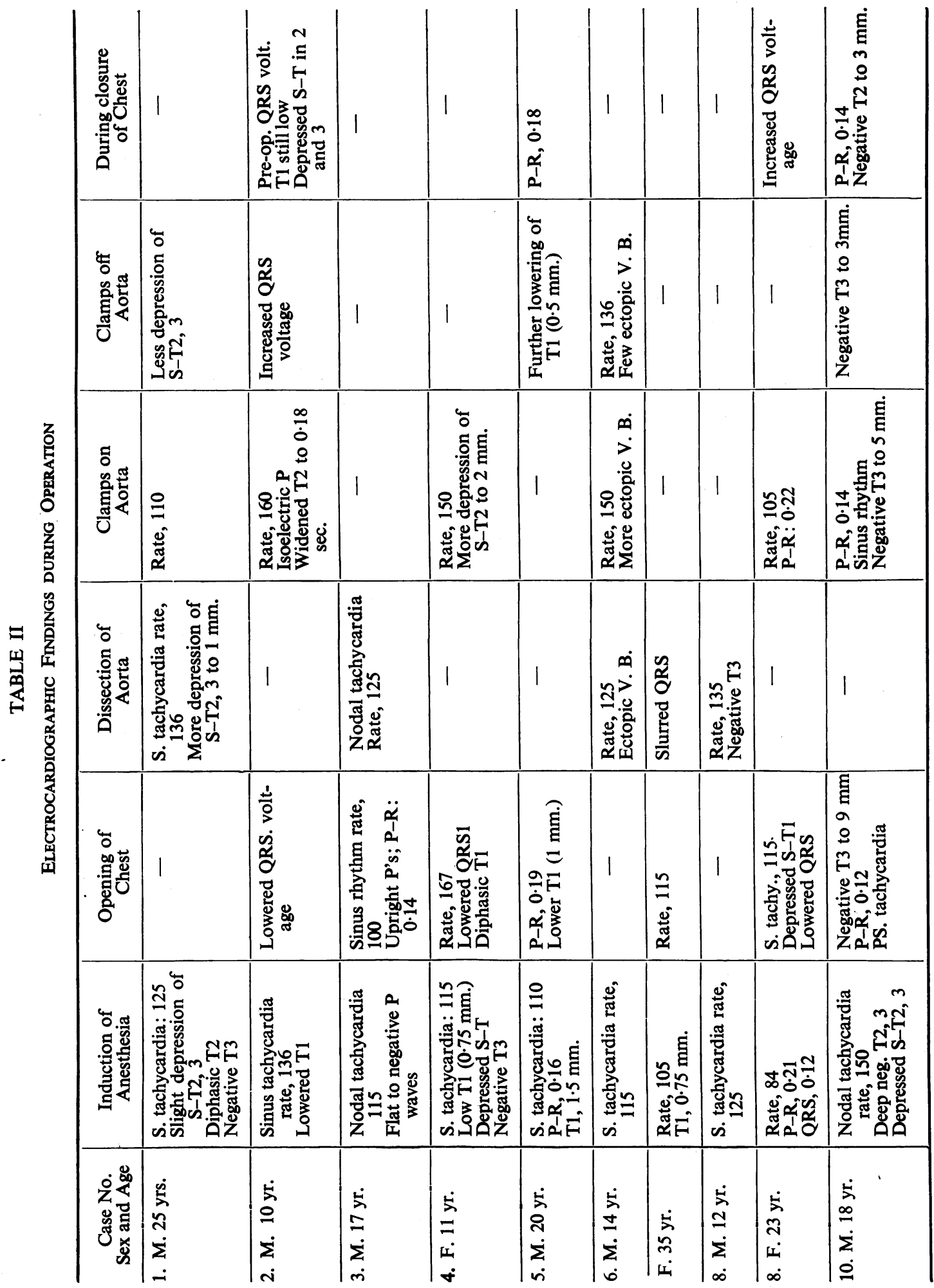




\section{Discussion}

The sinus tachycardia that occurred in our cases presumably was an effect of the anæsthetic agent used-ether. Thus, this increase in heart rate developed before the opening of the chest and persisted throughout the entire procedure. In the two cases with nodal rhythm (Fig. 1), the fact

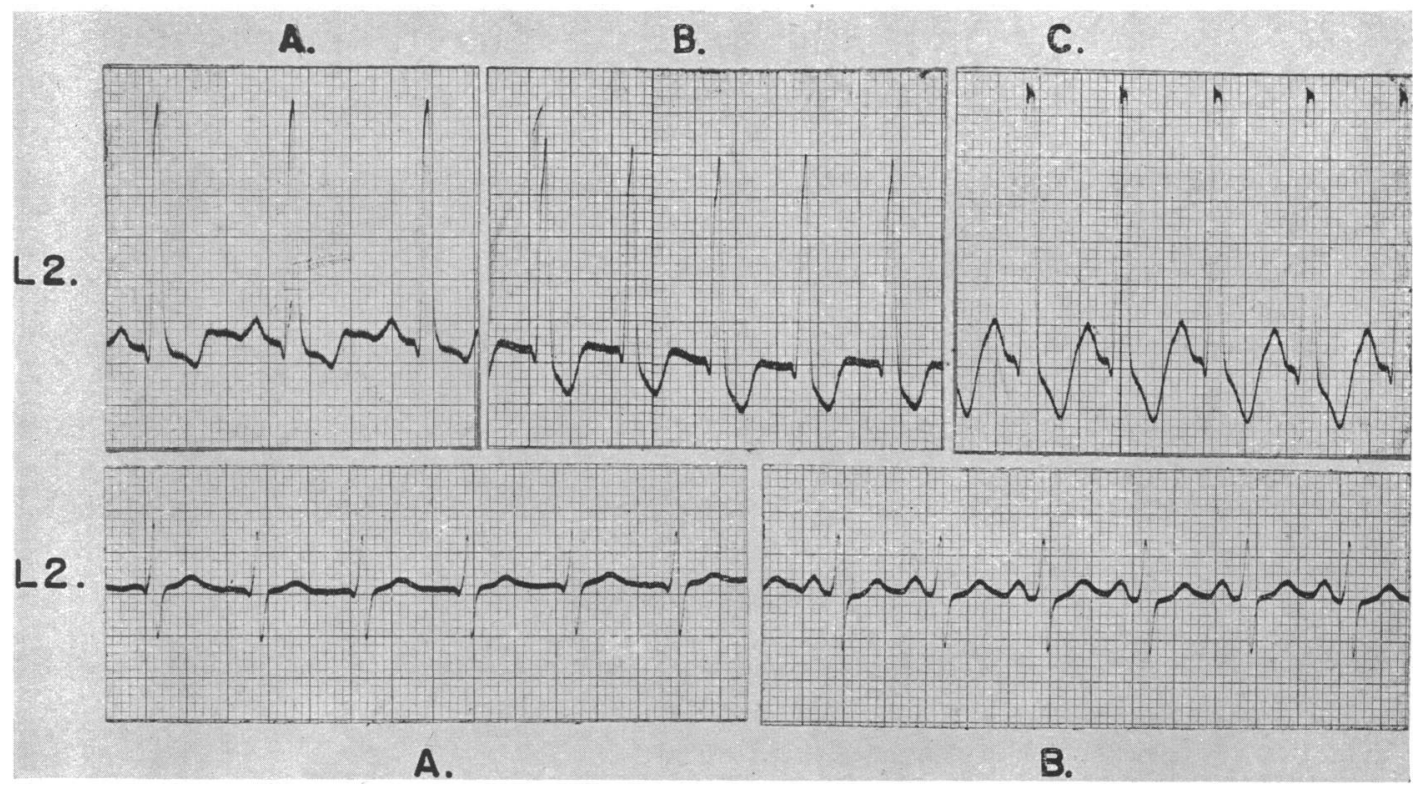

Fig. 1.

Upper curves. Case 10, lead 2. (A) Normal sinus rhythm before operation; (B) nodal tachycardia, during induction of anæsthesia; and (C) sinus tachycardia, during opening of the chest and the rest of the operation.

Lower curves. Case 3, lead 2. (A) Nodal rhythm during induction of anæsthesia; and (B) sinus rhythm, during opening of the chest. After the latter, nodal rhythm again developed and persisted throughout the rest of the operation. Sinus rate pre-operatively was 82 a minute.

that the ventricular rate then was faster than when it was under normal sinus control indicates that there was more than a simple depression of the sinus node. Under ordinary circumstances, nodal rhythm should have a slower rate than the sinus rhythm. It seems logical to consider, as Ziegler (1948) observed in his series, that an A-V nodal rhythm with a faster ventricular response than during the preceding normal sinus rhythm, is a true active ectopic nodal tachycardia. In 129 instances of A-V nodal rhythm, Ziegler found $33(25 \%)$ in which this active ectopic nodal tachycardia occurred. As in his cases, our own would suggest an interplay of several factors. Depression of the S-A node was probably mediated through the vagus, both by the morphine administered pre-operatively and by incidental vagal stimulation during the mediastinal dissection. On the other hand, the heightened irritability of the lower pacemaker, the A-V node in our cases, may be due partly to the morphine itself but more probably to ether. This is also true with the occurrence of ectopic ventricular beats in Case 6 (Fig. 2A). It is of interest, however, that none of these disturbances was severe in any of our cases. The tachycardia, sinus or nodal, never rose to unusual rates, and the ectopic ventricular beats were never multifocal nor unusually frequent. That no serious arrhythmia developed is somewhat against the frequency of its occurrence reported in studies by other authors done during intrathoracic surgery (Feil et al., 1939, and Currens et al., 1943). It is felt that this may be due to their use of cyclopropane (Kurtz et al., 1936, Taylor, 1941, and Theines, et al., 1941), which is known to increase the irritability of the myocardium.

Another evidence of vagal influence is the prolongation of $\mathrm{A}-\mathrm{V}$ conduction that occurred in 
2 cases (Fig. 2B and 3). While Ziegler observed only one instance of P-R prolongation, Burstein et al. (1949) and Gullickson and Campbell (1949) noted the development of this delayed A-V conduction during vagotomy and during vagus nerve stimulation incidental to pulmonary hilar traction and bronchial manipulation.

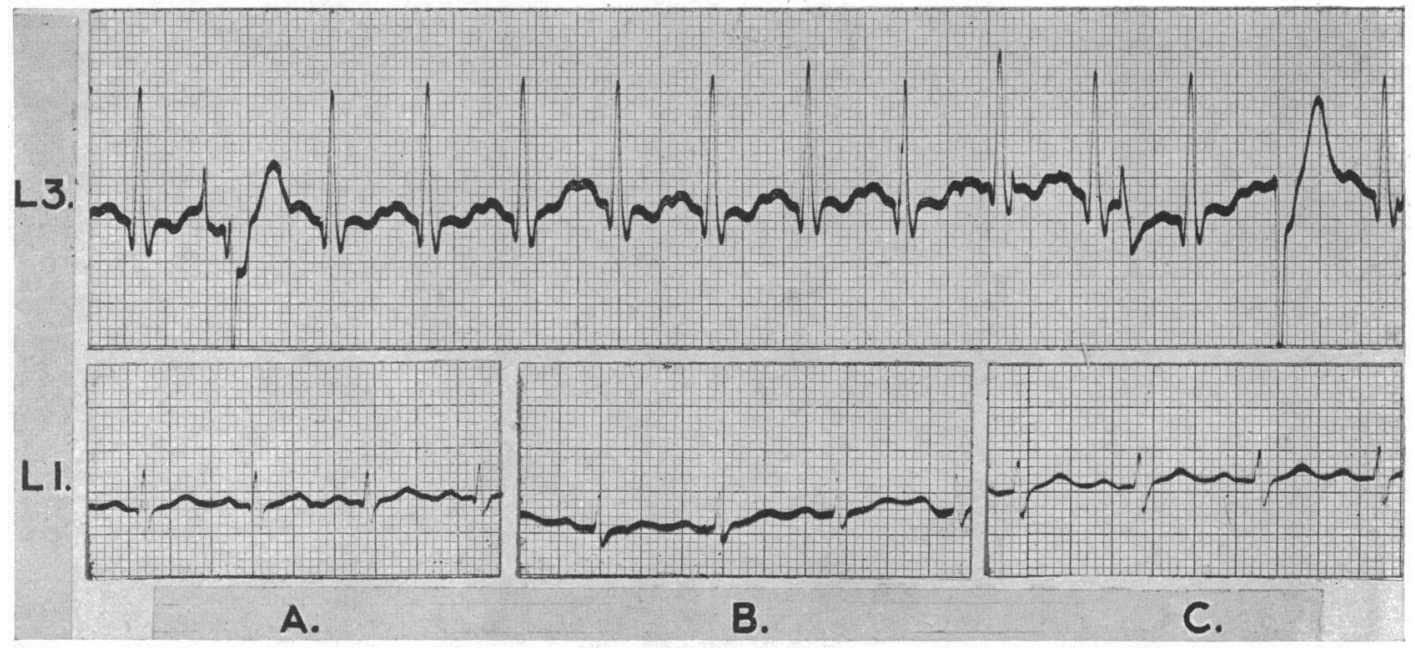

FIG. 2.

Upper curves. Case 6, lead 3. Ectopic ventricular beats and sinus tachycardia, both of which were more frequent at the time of clamping of the aorta as shown here.

Lower curves. Case 5, lead 1. Slight P-R changes during the operation. (A) P-R of 0.16 sec., pre-operatively and during induction of anæsthesia; (B) $P-R$ of $0.19-0.20 \mathrm{sec}$. during opening of the chest; (C) $P-R$ of 0.18 sec. during closure of the chest.

The QRS lowering, slurring, or aberration was never severe in degree and was probably caused by changes in heart position during the operation. However, when associated with S-T and/or T wave changes (Fig. 3 and 4), they were probably on the basis of myocardial hypoxia. Thus, they tended to be greatest when the chest was opened and the lung collapsed. The improvement of these changes towards the end of the operation and during the closure of the chest gives further support to this.

As a whole, therefore, no alarming electrocardiographic abnormalities occurred even during the critical phases of the operation pointed out earlier in this paper. There is, however, some indication from Table II that the changes noted here occurred or were apt to be more marked during the clamping of the aorta and at times slightly earlier, that is, during mediastinal exploration and dissection of the aorta prior to its clamping. This tendency involved essentially all the changes observed in these 10 cases. It is probable then that the underlying mechanism is an interplay of vagal influence and myocardial hypoxia.

From earlier experiences it was believed desirable, if possible, to reduce the blood pressure to approximately 140 or $150 \mathrm{~mm}$. Hg. systolic before clamping of the aorta. The measures taken were pre-operative sedation with morphine, and delaying the replacement of blood during the early phases of the operation. In our cases the average blood pressure immediately prior to clamping was 141/94 mm. In all instances this pre-clamping level was much lower than that before operation. The average blood pressure on admission was $175 / 99 \mathrm{~mm}$. In Case 10, it came down from $200 / 80$ on admission to $120 / 90 \mathrm{~mm}$. at the time of the clamping.

After placing of the aortic clamps, the average blood pressure was $165 / 107 \mathrm{~mm}$., which meant an average rise of $24 \mathrm{~mm}$. systolic and $13 \mathrm{~mm}$. diastolic over the pre-clamping level. The highest individual rise was in Case 1, where the pre-clamping level of 150/104 rose to 214/154 during the 
clamping; this unusual rise was probably related to the clamping of the subclavian artery which was necessary in this case during the aortic resection and anastomosis. In Case 8, there was no significant rise during the clamping, the blood pressure remaining at about $140 / 100 \mathrm{~mm}$.

It is clear that cardiac disturbances are an actual potential danger, as suggested by the observation here noted; namely, the tendency of all electrocardiographic abnormalities to occur or to be more

A.

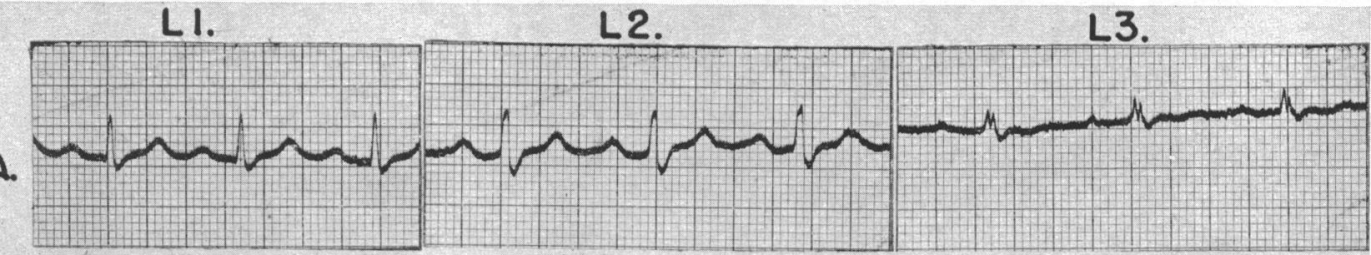

B.

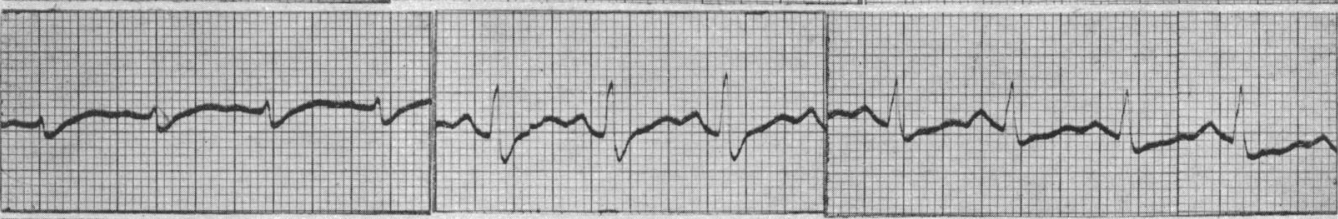

C.

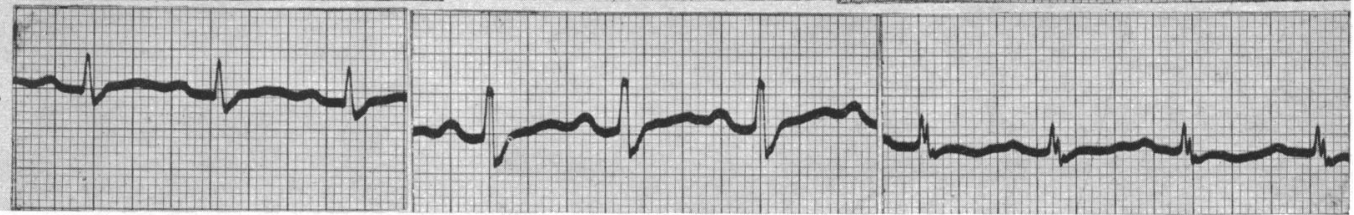

Fig. 3.-Case 9, leads 1, 2 and 3. (A) Pre-operatively and during earlier phases of operation: P-R of 0.20-0.21 sec. and QRS of 0.12 sec. (B) During clamping of the aorta: faster rate, lowering of QRS1 and T waves, S-T depression, P-R of 0.22 sec. and QRS of $0.12 \mathrm{sec}$. (C) During chest closure and end of operation: increase in $Q R S$ voltage and $T$ waves in lead 1 , with the same $P-R$ and $Q R S$ intervals.

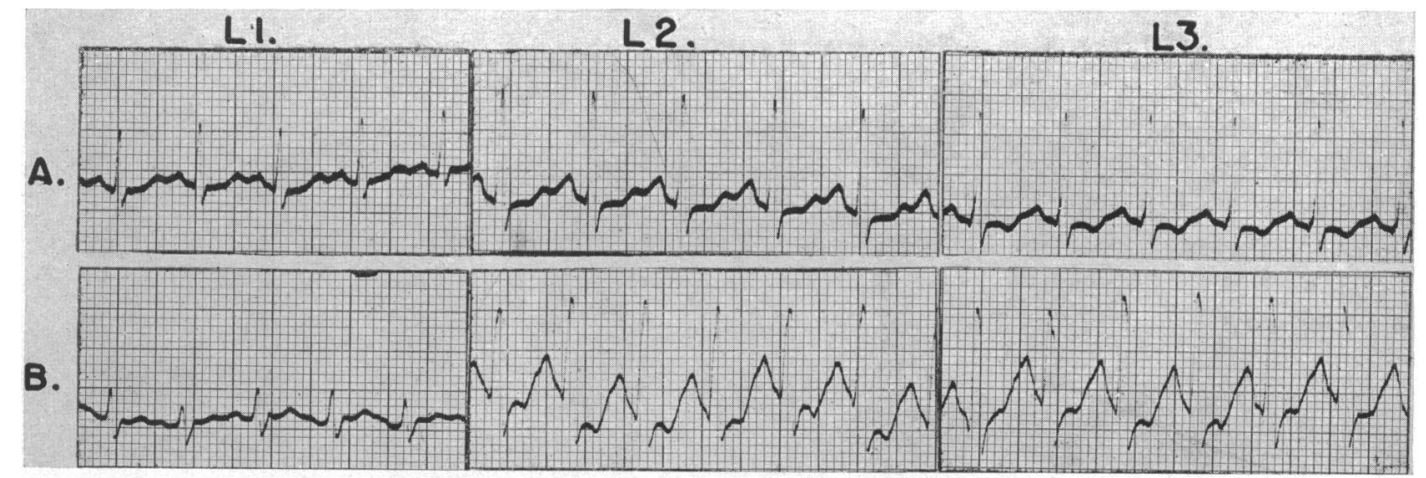

FIG. 4.-Case 4, leads 1, 2, and 3. (A) Pre-operatively and during induction of anæsthesia: some S-T depression more marked in lead 2, and negative $T$ in lead 3. (B) During clamping of the aorta: more rapid rate, lowered QRS in lead 1, lowered to diphasic or negative $T$ waves, and $S-T$ depression.

marked during this phase of the operation. This confirms the impression formed in some of the earlier cases of the existence of such a danger. While no direct proof can be provided, it seems probable that the absence of serious cardiac disturbances may have been in some measure due to the precautions previously mentioned to prevent excessive rise of blood pressure following the clamping of the aorta.

In contrast, during and following the release of the aortic clamps, not only was there no further $\mathbf{P}$ 
electrocardiographic abnormality noted but instead signs of improvement already started to appear. This was indicated by the improvement of the QRS voltage and configuration as well as of the S-T and $T$ wave abnormalities that may have occurred earlier (Fig. 3). That this should occur is to be expected as the factors producing myocardial hypoxia are removed and as a return of the cardiodynamics towards normal is started. This also confirms the importance of a gradual release of the aortic clamps. Complications were noted in the past at this stage of the operation in cases where the aortic clamps were released suddenly or rapidly. In our cases, the average blood pressure after removal of the aortic clamps was $115 / 75 \mathrm{~mm}$. The maximum drop was $90 \mathrm{~mm}$. systolic and $50 \mathrm{~mm}$. diastolic from the highest rise reached during the clamping. The lowest individual level was 100/80 and the highest was $140 / 100 \mathrm{~mm}$. In no instance did the blood pressure drop to shock levels.

Finally, the continued improvement of the electrocardiogram up to the completion of the operation offers evidence of the expected return of the circulation towards normal following the removal of the aortic block.

One other interesting observation from this study is the fact that P-R or QRS prolongation, unless of severe degrees, is not an absolute contraindication to this operation nor do they constitute an unusually serious risk. In fact, there may be some transient lengthening of the $\mathrm{P}-\mathrm{R}$ interval during the operation, presumably on the basis of vagal influence. On the other hand, the two cases with slight prolongation of the QRS interval maintained this (Fig. 3) throughout the operation, which suggests that the operation does not aggravate this abnormality. This is confirmed by a recent case of Littman and Warren (personal communication), a patient who had complete left bundle branch block with the same QRS duration of 0.14 sec. before and after the operation. These observations, though limited, are of practical interest inasmuch as some of the unsuccessful cases in the past had been attributed to pre-existing P-R and/or QRS prolongation. They also suggest that for the evaluation of the surgical risk the state of myocardial function is a more critical basis than are minor disturbances in conduction or rhythm.

\section{SumMaRY AND CONCLUSIONS}

Ten cases of coarctation of the aorta were studied from the point of view of electrocardiographic changes during the operation. The surgical procedure was resection of the coarctation followed by either end-to-end anastomosis or else insertion of an aortic graft. Ether was the anæsthetic agent used in all cases.

Several abnormalities were noted in the electrocardiograms before operation. They were chiefly evidences of left ventricular hypertrophy, and in a few instances also mild P-R or QRS prolongation.

The electrocardiographic abnormalities further observed during the operation, either in cardiac rhythm, conduction or ventricular activity, are tabulated and discussed: None of these was considered serious. The changes tended to occur or to be more marked towards and during the clamping of the aorta. No further abnormality was noted either during the release of the aortic clamps or immediately after the operation. Instead, the electrocardiogram started to show signs of improvement from the time the aortic clamps were released.

The two cases who had or developed P-R prolongation as well as those with slight QRS prolongation suggest that such conduction defects, unless severe, are not absolute contraindications to the operation.

The authors are indebted to Dr. Robert E. Gross for making this study possible.

\section{REFERENCES}

Ashman, R., and Hill, E. (1941). Essentials of Electrocardiography. Lea and Febiger, Philadelphia.

Burch, G. E., and Winsor, T. (1949). A Primer of Electrocardiography. Lea and Febiger, Philadelphia, 2nd ed.

Burstein, C. (1946). Anesthesiology, 7, 113.

Burstein, C. L., and Alexander, F. A. D. (1947). Ibid. 8, 36.

- Piazza, T. L., Kapp, L. A., and Rovenstene, E. A. (1949). Surgery, 25, 36.

Claggett, O. T. (1949). Proc. Staff Meet. Mayo Clin., 25, 359.

Currens, J. H., White, P. D., and Churchill, E. D. (1943). New Eng. J. Med., 229, 360.

Dripps, R. D. (1947). Anesthesiology, 8, 15. 
Feil, H., and Rossman, P. L. (1939). Ann. intern. Med., 13, 402.

Gross, R. E. (1945). Surgery, 18, 673 and 20, 41.

(1945). J. Amer. med. Ass., 139, 285.

(1950). Circulation, 2, 41.

Gullickson, M. J., and Campbell, D. A. (1949). Surg. Gyn. Obst., 89, 153.

Kurtz, C. M., Bennett, J. H., and Shapiro, H. H. (1936). J. Amer. med. Ass., 106, 434.

Meek, W. J., Hathaway, H. R., and Orth, O. S. (1937). J. Pharmacol. Exper. Therap., 61, 240.

Reifenstein, G. A., Levine, S. A., and Gross, R.E. (1947). Amer. Heart J., 33, 146.

Shapiro, M. J. (1949). Ibid, 37, 1045.

Sloan, H. E. (1949). Paper presented at the 35th Clinical Congress of Amer. Coll. Surg., Chicago, Ill.

Taylor, I. A. (1941). Anesthesiology, 2, 641 .

Theines, C. H., Greeley, P. O., and Guedel, A. E. (1941). Anesthesiology, 2, 511.

Ziegler, R. F. (1948). Bull. Johns Hopkins Hosp., 83, 237. 